\title{
Midgut pain due to an intussuscepting terminal ileal lipoma: a case report
}

Noormuhammad O Abbasakoor', Dara O Kavanagh, Diarmaid C Moran, Barbara Ryan², Paul C Neary ${ }^{1 *}$

\begin{abstract}
Introduction: The occurrence of intussusception in adults is rare. The condition is found in 1 in 1300 abdominal operations and 1 in 100 patients operated for intestinal obstruction. The child to adult ratio is 20:1.

Case presentation: A 52-year-old Irish Caucasian woman was investigated for a 3-month history of intermittent episodes of colicky midgut pain and associated constipation. lleocolonoscopy revealed a pedunculated lesion in the terminal ileum prolapsing into the caecum. Computed tomography confirmed a smooth-walled,

nonobstructing, low density intramural lesion in the terminal ileum with secondary intussusception. A laparoscopic small bowel resection was performed. Histology revealed a large pedunculated polypoidal mass measuring $4 \times 2.5$ $\times 2 \mathrm{~cm}$ consistent with a submucosal lipoma. She had complete resolution of her symptoms and remained well at 12-month follow-up.

Conclusion: This case highlights an unusual cause of incomplete small bowel obstruction successfully treated through interdisciplinary cooperation. Ileal lipomas are not typically amenable to endoscopic removal and require resection. This can be successfully achieved via a laparoscopic approach with early restoration of premorbid functioning.
\end{abstract}

\section{Introduction}

Neoplasms of the small intestines are rare [1]. Gastrointestinal lipomas are benign tumors that can occur in the small bowel but occur most commonly in the colon. The majority are asymptomatic and are detected incidentally on abdominal imaging. Removal is warranted if tissue diagnosis is deemed essential or if severe symptomatology, such as pain or bleeding, exists [2].

We report a case of terminal ileal lipoma causing intermittent intussusception in a 52-year-old woman. The lipoma was diagnosed at ileocolonoscopy and successfully removed through laparoscopy. A review of the literature on small bowel intussception and gastrointestinal (GI) lipomas is also presented in this report.

\section{Case presentation}

A 52-year-old Irish Caucasian woman presented with a three-month history of intermittent central abdominal pain and constipation. She did not describe gastrointestinal bleeding or weight loss. She previously underwent a

\footnotetext{
* Correspondence: paulcneary@msn.com

'Division of Colorectal Surgery, Adelaide and Meath Incorporating the National Children's Hospital, Tallaght, Dublin 24, Ireland
}

transabdominal hysterectomy for menorrhagia. Her physical examination was unremarkable. Initial investigations, such as blood tests, abdomen ultrasound and gastroscopy were unremarkable. Ileocolonoscopy revealed a pedunculated terminal ileal lesion prolapsing into her caecum. Computed tomography (CT) of her abdomen and pelvis demonstrated a smooth-walled, low-density, intramural lesion in the terminal ileum. It measured $3.2 \times 1.6 \mathrm{~cm}$. The ileum at the proximal end of the lesion was mildly dilated with a centrally placed narrowed channel of contrast, which was consistent with an intussusception possibly secondary to an intramural lipoma. There was no evidence of obstruction (Figure 1).

She underwent an elective laparoscopic small bowel resection and stapled functional end-to-end anastomoses. On macroscopy the lesion appeared as a large pedunculated polypoid mass measuring $4 \times 2.5 \times 2 \mathrm{~cm}$ with focal mucosal ulceration (Figure 2). Microscopy revealed a submucosal lipoma with blunting of the overlying mucosal villi and pyloric gland metaplasia. She made an uneventful recovery and was discharged home on the fourth postoperative day. She returned to work 


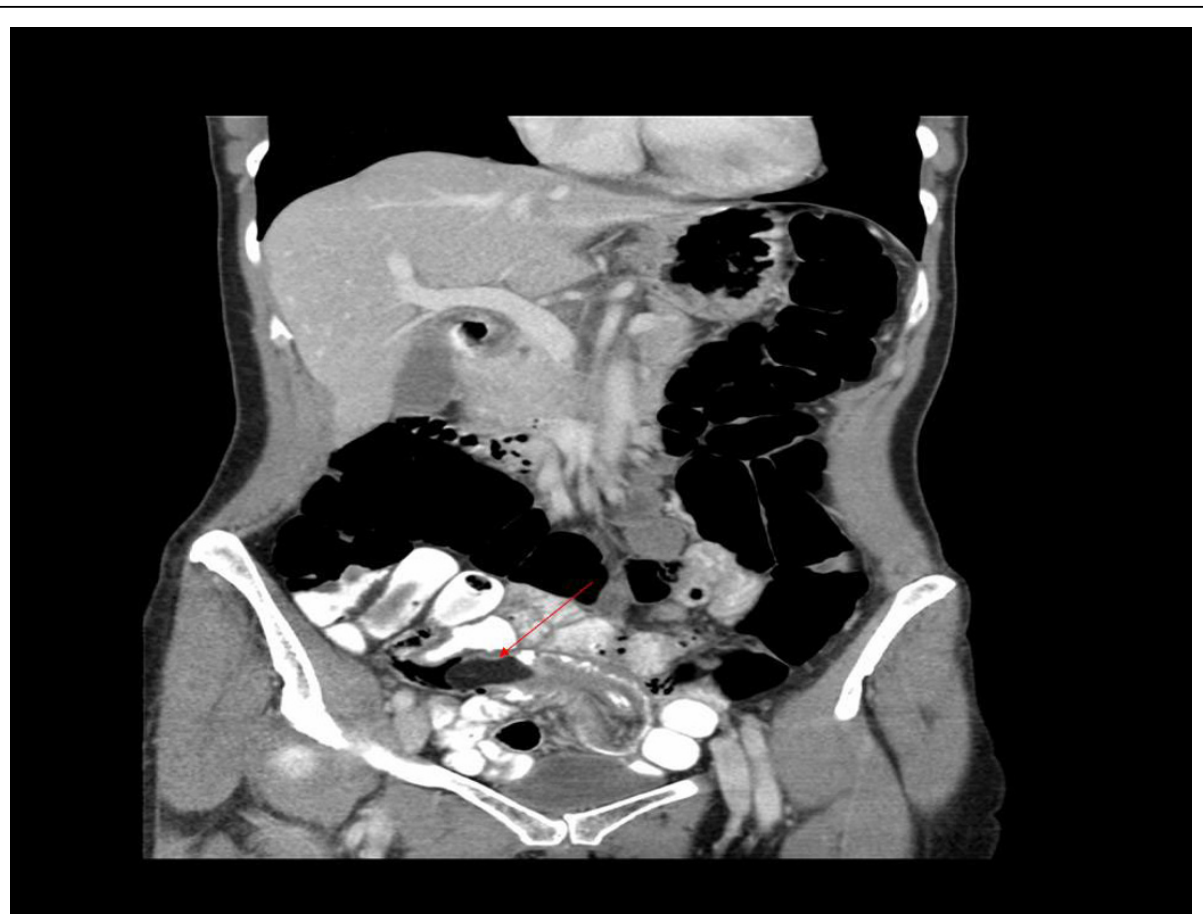

Figure 1 Contrast-enhanced computed tomography scan of the abdomen demonstrates a smooth-walled, low-density intramural lesion. It measures $3.2 \times 1.6 \mathrm{~cm}$. The ileum at the proximal end of the lesion is mildly dilated with a centrally placed narrowed channel of contrast consistent with an intussusception.

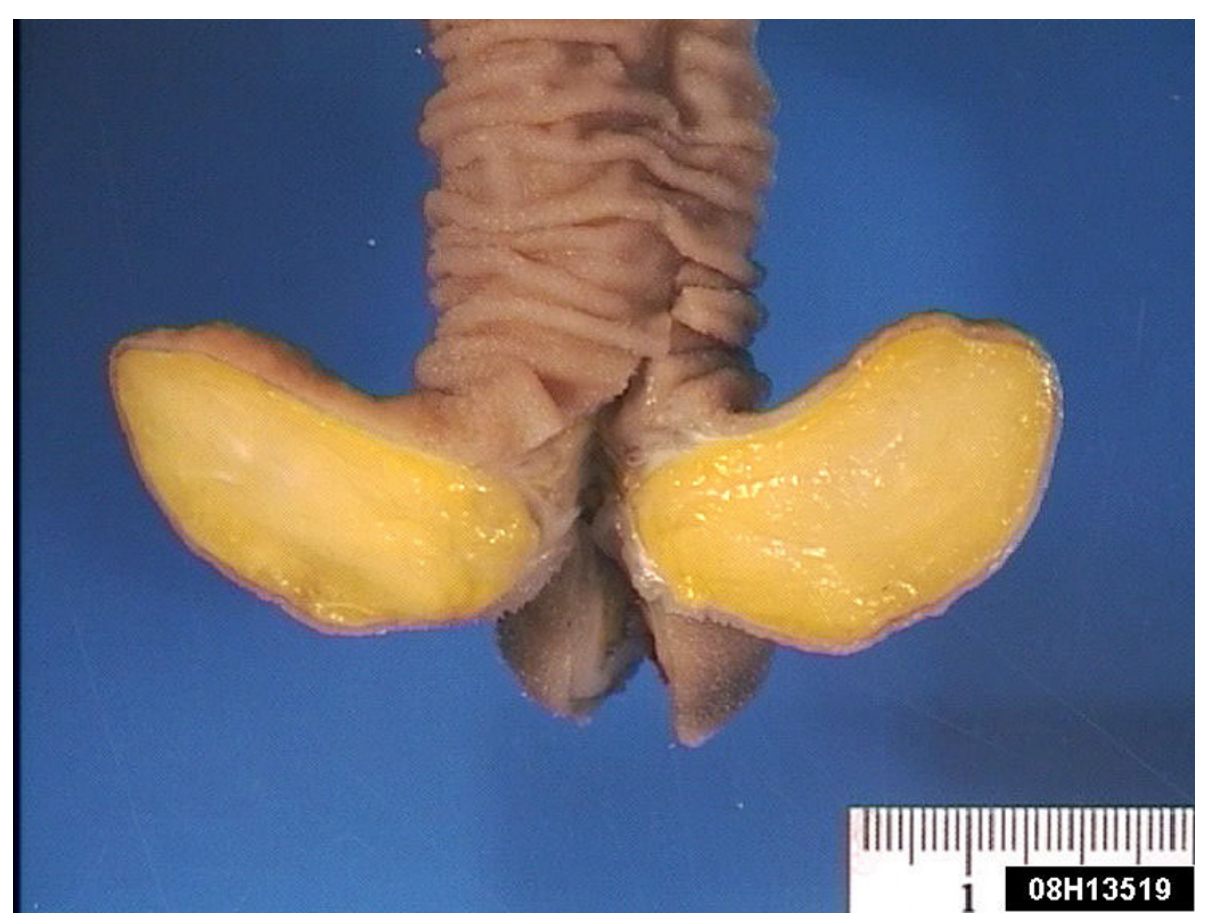

Figure 2 Macroscopic view of a large pedunculated polypoid mass arising from the luminal surface of the ileal resection specimen Appearances are consistent with a lipoma. 
on the $12^{\text {th }}$ postoperative day. She remained free of symptoms at three-month follow-up.

\section{Discussion}

Lipomas are benign tumors of mesenchymal origin. They are the second most common benign tumors in the small intestine and account for $10 \%$ of all benign gastrointestinal tumors and 5\% of all gastrointestinal tumors. They are predominantly submucosal and protrude into the lumen [2]. Occasionally, they arise in the serosa. Gastrointestinal lipomas are most commonly located in the colon ( $65 \%$ to $75 \%$, especially on the right side), small bowel (20\% to $25 \%$ ), and occasionally in the foregut $(<5 \%)$ [2]. Lipomas are largely asymptomatic. Major presenting features are intestinal obstruction and hemorrhage [3].

Intussusception in adults is a rare entity that it is generally caused by definable intraluminal pathology [4]. Diagnosis can be challenging. Intussusception is classified according to its gastrointestinallocation: enteric, ileocaecal, or colonic [4]. In ileocaecal intussusceptions, the ileocaecal valve acts as the lead point. The ileum ('intussusceptum') telescopes into the colon ('intussuscipiens') through the ileocaecal valve [5,6]. Intussusception leads to the development of venous and lymphatic congestion, which results in intestinal edema. If not treated promptly, the arterial blood supply to the bowel will be compromised, thus leading to ischaemia, perforation and peritonitis [4]. Only $5 \%$ of all intussusceptions occur in adults [7]. In $90 \%$ of these cases a predisposing lesion is identified [7]. This is contrary to intussusception in the pediatric population where an organic lesion is found in only $10 \%$ of documented cases [3]. In adults, it is important to differentiate between small bowel and colonic intussusception. In $63 \%$ of cases of small bowel intussusceptions, a benign underlying lesion can be found. Meanwhile, a malignant etiology has to be expected in $58 \%$ of cases of large bowel intussusceptions [8].

Lipomas can be diagnosed through conventional endoscopy, capsule endoscopy, barium studies and, most importantly, CT. Typical endoscopic features are smooth, yellowish surface with pedunculated or sessile base, as seen in this case. Other endoscopic characteristics are the "cushion sign" and "naked fat sign" [2]. CT usually reveals a smooth, well-demarcated sausageshaped mass. It may also reveal associated intussusception if present [5]. Capsule endoscopy and digital balloon endoscopy are newer means for diagnosing lipomas and are particularly helpful in cases involving small bowel lipomas [2]. Associated intussusception can be confirmed on contrast enema ('crescent sign'), CT and magnetic resonance imaging (MRI). Multislice CT facilitates the assessment of vascular supply to the affected bowel loop in cases of intussusception where impending ischemia is suspected [4].

The treatment for lipomas depends on the clinical manifestations. Indications for their removal include intestinal obstruction, hemorrhage and malignant potential [4]. There is a theoretical risk of sarcomatous change but this has rarely been documented in the literature [1]. Endoscopic removal is possible but potentially complicated. In view of the submucosal location, there is an inherent risk of perforation [9]. Furthermore, lipomas have high water content, which means a large amount of cautery is necessary to achieve effective hemostasis [9]. Surgery can be performed through laparoscopy or via an open approach. The type of resection and anastomosis depends on the location, bowel wall integrity, and vascular supply of the lipoma [6]. Elective laparoscopic resection of lipomas is the treatment of choice with the concomitant benefits of laparoscopic surgery, such as shorter duration of hospital stay, less postoperative pain, early restoration of (GI) function and good cosmesis [6].

\section{Conclusion}

In this case, we illustrate the importance of a thorough interdisciplinary evaluation of patients with midgut abdominal pain. It highlights the diagnostic values of CT scanning and completed ileocolonoscopy. Despite preoperative localization, laparoscopy facilitates a thorough evaluation of the intraperitoneal contents and therapeutic resection of the affected segment. This report confirms the recognized benefits of laparoscopic surgery with associated early return to premorbid functioning. In patients with persistent episodes of incomplete intestinal obstruction, atypical causes, such as the etiology we describe here, should be considered.

\section{Consent}

Written informed consent was obtained from our patient for publication of this case report and any accompanying images.

\section{Author details}

'Division of Colorectal Surgery, Adelaide and Meath Incorporating the National Children's Hospital, Tallaght, Dublin 24, Ireland. ${ }^{2}$ Department of Gastroenterology, Adelaide and Meath Incorporating the National Children's Hospital, Tallaght, Dublin 24, Ireland.

\section{Authors' contributions}

NOA contributed in collecting the requisite literature and wrote the case report. DOK also collected the requisite literature and reviewed the literature. DCM also contributed in collecting the requisite literature. BR and PCN were involved in the diagnosis of our patient. PCN also performed the surgery. All authors read and approved the final manuscript.

\section{Competing interests}

The authors declare that they have no competing interests. 


\section{References}

1. Rathore MA, Andrabi SI, Mansha M: Adult intussusception: a surgical dilemma. J Ayub Med Coll Abbottabad 2006, 18(3):3-6.

2. Chou JW, Feng CL, Lai HC, Tsai CC, Chen SH, Hsu CH, Cheng KS, Peng CY, Chung PK: Obscure gastrointestinal bleeding caused by small bowel lipoma. Inter Med 2008, 47:1601-1603.

3. Balik AA, Ozturk G, Aydinli B, Alper F, Gumus H, Yildirgan Ml, Basoglu M: Intussusception in adults. Acta Chir Belg 2006, 106(4):409-412.

4. Lin HH, Chan DC, Yu CY, Chao YC, Hsieh TY: Is this a lipoma?. Am J Med 2008, 121(1):21-23.

5. Michael A, Dourakis S, Papanikolaou I: lleocaecal intussusception in an adult caused by a lipoma of the terminal ileum. Ann Gastroenterol 2001, 14(1):56-59.

6. Takaaki T, Matsui N, Hiroshi K, Takemoto Y, Oka K, Seyama A, Morita T: Laparoscopic resection of an ileal lipoma: report of a case. Surg Today 2006, 36:1007-1011.

7. Meshikhes AW, Al-Momen SA, Al Talaq FT, Al-Jaroof AH: Adult intussusception caused by a lipoma in the small bowel: report of a case. Surg Today 2005, 35(2):161-165.

8. Oyen TL, Wolthuis AM, Tollens T, Aelvoet C, Vanrijkel JP: lleo-ileal intussusception secondary to a lipoma: a literature review. Acta Chir Belg 2007, 107:60-63.

9. Yoshimura H, Murata K, Takase K, Nakano T, Tameda Y: A case of lipoma of the terminal ileum treated by endoscopic removal. Gastrointestinal Endosc 1997, 46(5):461-463.

doi:10.1186/1752-1947-4-51

Cite this article as: Abbasakoor et al:: Midgut pain due to an

intussuscepting terminal ileal lipoma: a case report. Journal of Medical Case Reports 2010 4:51.

\section{Submit your next manuscript to BioMed Central and take full advantage of:}

- Convenient online submission

- Thorough peer review

- No space constraints or color figure charges

- Immediate publication on acceptance

- Inclusion in PubMed, CAS, Scopus and Google Scholar

- Research which is freely available for redistribution

Submit your manuscript at www.biomedcentral.com/submit 